\title{
Genome-wide analysis of the basic leucine zipper (bZIP) transcription factor gene family in six legume genomes
}

Zhihui Wang, Ke Cheng, Liyun Wan, Liying Yan, Huifang Jiang, Shengyi Liu, Yong Lei* and Boshou Liao*

\begin{abstract}
Background: Plant bZIP proteins characteristically harbor a highly conserved bZIP domain with two structural features: a DNA-binding basic region and a leucine (Leu) zipper dimerization region. They have been shown to be diverse transcriptional regulators, playing crucial roles in plant development, physiological processes, and biotic/ abiotic stress responses. Despite the availability of six completely sequenced legume genomes, a comprehensive investigation of bZIP family members in legumes has yet to be presented.

Results: In this study, we identified 428 bZIP genes encoding 585 distinct proteins in six legumes, Glycine max, Medicago truncatula, Phaseolus vulgaris, Cicer arietinum, Cajanus cajan, and Lotus japonicus. The legume bZIP genes were categorized into 11 groups according to their phylogenetic relationships with genes from Arabidopsis. Four kinds of intron patterns (a-d) within the basic and hinge regions were defined and additional conserved motifs were identified, both presenting high group specificity and supporting the group classification. We predicted the DNA-binding patterns and the dimerization properties, based on the characteristic features in the basic and hinge regions and the Leu zipper, respectively, which indicated that some highly conserved amino acid residues existed across each major group. The chromosome distribution and analysis for WGD-derived duplicated blocks revealed that the legume bZIP genes have expanded mainly by segmental duplication rather than tandem duplication. Expression data further revealed that the legume bZIP genes were expressed constitutively or in an organ-specific, development-dependent manner playing roles in multiple seed developmental stages and tissues. We also detected several key legume bZIP genes involved in drought- and salt-responses by comparing fold changes of expression values in drought-stressed or salt-stressed roots and leaves.
\end{abstract}

Conclusions: In summary, this genome-wide identification, characterization and expression analysis of legume bZIP genes provides valuable information for understanding the molecular functions and evolution of the legume bZIP transcription factor family, and highlights potential legume bZIP genes involved in regulating tissue development and abiotic stress responses.

Keywords: bZIP gene family, Legume genomes, Evolution, Expression analysis

\footnotetext{
*Correspondence: leiyong@caas.cn; Iboshou@hotmail.com

Key Laboratory of Biology and Genetic Improvement of Oil Crops, Ministry of

Agriculture, Oil Crops Research Institute of the Chinese Academy of

Agricultural Sciences, Wuhan, China
} 


\section{Background}

A defining feature of transcription factors is that they contain one or more sequence-specific DNA-binding domains that bind to the promoter and/or enhancer regions of target genes to regulate gene expression $[1,2]$. The basic leucine (Leu) zipper (bZIP) transcription factor family, one of the most diverse transcription factors families, is characterized by a highly conserved bZIP domain which is 60-80 amino acids in length and composed of two parts: a basic region and a Leu zipper [3]. The basic and Leu zipper regions are structurally and functionally distinct. The basic region comprises approximately 16 amino acid residues with the invariant motif $\mathrm{N}-\mathrm{x} 7-\mathrm{R} / \mathrm{K}-\mathrm{x} 9$ and is responsible for nuclear localization and DNA binding, whereas the Leu zipper is composed of heptad repeats of Leu or other bulky hydrophobic amino acids positioned exactly nine amino acids towards the C-terminus and mediates homo- and/ or heterodimerization of bZIP proteins $[1,2]$. bZIP transcription factor encoding genes have been identified extensively in plants including Arabidopsis [4], rice [5], sorghum [6], maize [7], grapevine [8], cucumber [9], castor bean [10] and barley [11] with the availability of their whole genome sequences.

Like other transcription factors, members of the bZIP transcription factor family are expressed constitutively or in an organ-specific [12, 13], stimulus-responsive [14], development-dependent [15] or cell cycle-specific [16] manner in plants. It has been reported that bZIP transcription factors are involved in various biological processes including organ and tissue differentiation, embryogenesis, seed maturation and storage protein gene regulation, floral transition and initiation, and vascular development [17-21]. Moreover, bZIP transcription factors are also regarded as important regulators in signaling and responses to abiotic/biotic stimuli, including abscisic acid (ABA) signaling, hypoxia, drought, high salinity, cold stress, hormone and sugar signaling, light responses, osmotic stresses and pathogen defense $[7,12,22-26]$. In soybean, three bZIP genes were found to function as negative regulators of ABA signaling and confer salt and freezing tolerance in transgenic Arabidopsis [27].

In recent years, legume genome sequencing projects have been initiated and completed in Lotus japonicus $(L j)$ [28], soybean (Glycine max, Gm) [12], Medicago truncatula $(M t)$ [29], pigeonpea (Cajanus cajan, Cc) [30], chickpea (Cicer arietinum, $\mathrm{Ca}$ ) [31] and common bean (Phaseolus vulgaris, Pv) [32]. These six legumes belong to the large Papilionoideae subfamily and fall within two sub-clades of the Papilionoid legumes: the Phaseoloids (warm season legumes) and Hologalegina (cool season legumes). The Phaseoloids are mostly tropical and include the crops soybean $(G m)$, pigeonpea $(C c)$ and common bean $(P v)$, while the Hologalegina are mostly temperate and include Medicago $(\mathrm{Mt})$, chickpea $(\mathrm{Ca})$ and Lotus $(L j)$. Among the widespread genome duplications throughout the history of flowering plants [14, 33], two recent whole genome duplication (WGD) events have affected the evolution of legume genomes. The older polyploidy event, shared by all legumes, is estimated to have occurred 56-65 million years ago (Mya) [34, 35], while the more recent genome duplication event occurred up to 13 Mya only in the lineage leading to Glycine [12]. Genome duplication and subsequent fractionation have played key roles in shaping present-day legume genomes and also the sizes of gene families [36].

With the availability of these legume genome sequences, the members of the bZIP transcription factor family were systematically investigated and analyzed in this study. We identified all legume bZIP genes and analyzed their bZIP domain sequences, gene structure and additional MEME motifs, which was in agreement with and supported the phylogenetic classification. Then, we predicted the DNAbinding-site specificity and dimerization properties of the legume bZIP proteins. We also investigated the impact of the two legume-lineage WGDs and tandem duplication on the expansion of the legume bZIP gene family. By analyzing their expression profiles, legume bZIP genes constitutively or specifically expressed in different tissues and seed developmental stages were identified, as well as candidate legume bZIPs responsive to drought and salt stresses.

\section{Methods}

\section{Identification of bZIP transcription factors in six legume genomes}

All genomic sequences and annotated proteins of the six legumes were downloaded from ftp://ftp.jgi-psf.org/ pub/compgen/phytozome/v9.0/Gmax/ (G. $\max , \mathrm{v9}$ ), http://jcvi.org/medicago/display.php?pageName=General\&section=Download (M. truncatula, v4.0), http://gen ome.jgi.doe.gov/pages/dynamicOrganismDownload.jsf? organism $=$ PhytozomeV10 (P. vulgaris, v10), http:// cicar.comparative-legumes.org/ (C. arietinum, chickpea, v1.0), http://www.icrisat.org/gt-bt/iipg/Genome_Manuscript.html (C. cajan, v1.0) and ftp://ftp.kazusa.or.jp/ pub/lotus/lotus_r2.5/ (L. japonicus, v2.5).

To identify all the possible bZIP proteins in the six legume genomes, both local BLAST and hidden Markov model (HMM, http://hmmer.org/) searches were performed. For BLASTP, the known bZIP proteins from Arabidposis [4], rice [5] and maize [7] were used as queries and the e-value was set to 1e-5. For the HMM search, the profile of bZIP domain was used and the evalue threshold was set at 1 . The sequences were further analyzed to confirm the presence and integrity of the bZIP domain through the ExPASy Proteomics Server (http://pro site.expasy.org/) [37] and Interpro (http://www.ebi.ac.uk/ 
interpro/) [38]. All bZIP domain sequences were aligned using MAFFT 7 [39] to manually check and remove sequences with incomplete domains. The nomenclature was based on the exact positions of the bZIP genes on the chromosomes/scaffolds from top to bottom. Distinct transcripts encoded by the same gene locus shared the same gene number with an additional decimal part, such as point 1 or 2 (Additional file 1).

\section{Sequence alignment and phylogenetic analysis}

The bZIP amino acid sequences from A. thaliana and the six legume genomes were aligned using ClustalX 2.0 [40] with gap opening and gap extension penalties of 10 and 0.1 , respectively. The phylogenetic tree was reconstructed by the maximum likelihood (ML) method using the PhyML 3.0 software [41]. JTT + G was selected as the best model for constructing the phylogenetic tree by the Akaike information criterion implemented in ProtTest 3.0 [42]. Bootstrap values from 100 replicates were indicated at each node. MEGA5 [43] was used to show the tree.

\section{Structure of bZIP genes}

The positional information of both the gene sequence and the corresponding coding sequence were loaded into the gene structure display server v2.0 (http://gsds.cbi.pku.edu.cn/) [44] to obtain information on the intron/ exon structure. The coordinates of the bZIP domain in each protein were recalculated into the coordinates in gene sequence and featured in gene structure. We used Genewise [45] to analyze the intron distribution pattern and intron splicing phase within the basic and hinge regions of the bZIP domains in the six legumes.

\section{Detection of additional conserved motifs}

To identify additional conserved motifs outside the bZIP domain of legume bZIP transcription factors, we used the Multiple Em (Expectation Maximization) for the Motif Elicitation tool (MEME version 4.9.1, http://meme.nbcr.net/meme/) [46]. The limits for maximum width, minimum width and maximum number of motifs were specified as 50, 10 and 100, respectively. Fifty motifs were finally confirmed because of their low e-values $(<1 \mathrm{e}-200)$. The motifs were numbered according to the order displayed in MEME and were considered as group-specific signatures for their presence of high frequency in the given groups.

\section{Detection of duplicated genes and estimation of synonymous (Ks) and nonsynonymous (Ka) substitutions per site and their ratio}

The duplicated gene pairs derived from segmental duplication were identified in the legume genomes based on the method from the Plant Genome Duplication Database
[23]. An all-against-all BLASTP comparison (e-value: $1 \mathrm{e}-5)$ provided the gene pairs for syntenic clustering determined by MCScan (using default settings: MATCH_SCORE: 50, MATCH_SIZE: 5, GAP_SCORE:-3, E_VALUE: 1E-05) (http://chibba.agtec.uga.edu/duplica tion/mcscan). Tandem duplication arrays were identified using BLASTP with a threshold of $\mathrm{e}<10^{-20}$, and one unrelated gene among cluster members was tolerated, as described in $A$. thaliana [26]. Pairs from segmental or tandem duplications were used to estimate $\mathrm{Ka}$, Ks and their ratio. Amino acid sequences from segmentally or tandemly duplicated pairs were first aligned and then guided and transferred into a cDNA sequences alignment using in-house Perl scripts. Then, the software KaKs_Calculator was used to compute Ka and Ks values for each pair following the YN model [24].

\section{Expression analysis of legume bZIP genes}

For different tissues/organ and seed developmental stages, the normalized counts for bZIP genes from RNA-seq were obtained from the Soyseq (http://www.soybase.org/) [47] and PvGEA (http://plantgrn.noble.org/PvGEA/) databases [48]. Microarray expression values for Medicago and Lotus were downloaded from http://mtgea.noble.org/v3/ [49, 50] and http://ligea.noble.org/ v2/ [51]. To identify candidate bZIP genes responsive to drought and/or salt stresses, microarray gene expression data in Medicago were downloaded from Zhang et al. [52] and Li et al. [53], respectively. The gene expression changes in drought-stressed roots and shoots (treatment at days 3, 4, 7, 10 and 14) were obtained by comparing with levels in the watered control (drought day 0). Similarly, the fold changes in gene expression were calculated when comparing the saltstressed roots (treatment with $180 \mathrm{mM} \mathrm{NaCl}$ at 6, 24, and $48 \mathrm{~h}$ ) and control (treatment at $0 \mathrm{~h}$ ). The corresponding relationships between microarray probes and legume bZIP genes were built using BLAST (best hit under 1e-10). The expression values or normalized counts were $\log 10$ transformed and the gplots package was used to make a heatmap in $\mathrm{R}$.

\section{Results and discussion}

Identification and nomenclature of the legume bZIP transcription factor family

Through sequence similarity and domain searches, 138 Gm, $65 \mathrm{Mt}, 72 \mathrm{Pv}, 59 \mathrm{Ca}, 61 \mathrm{Cc}$ and $33 \mathrm{Lj}$ bZIP genes, encoding 241, 99, 92, 59, 61 and 33 distinct proteins, respectively, were identified in the six legume genomes. Based on their exact positions on chromosomes/scaffolds (from top to bottom), we gave a unique name to each bZIP protein. The related information on bZIP transcription factors are listed in the Additional file 1.

Domain analysis showed that all 585 of the bZIP transcription factors except eight had a typical bZIP domain 
with an invariant $\mathrm{N}-\mathrm{x} 7-\mathrm{R} / \mathrm{K}$ motif in the basic region and a heptad repeat of Leu or other bulky hydrophobic amino acids positioned exactly nine amino acids upstream of $\mathrm{R} / \mathrm{K}$ toward the $\mathrm{C}$-terminus (Additional file 2). Of the remaining eight, in Glyma12g04933.1 (GmbZIP80) and Phvul.011G047100.1 (PvbZIP67), the conserved Asn $(\mathrm{N})$ in the basic region was replaced by Lys $(\mathrm{K})$. In Glyma03g35101.1 (GmbZIP21), Glyma19g37801.1 (GmbZIP128), Medtr7g104190.1 (MtbZIP52) and Ca_00780 (CabZIP15), the conserved Arg/Lys (R/K) in the basic region was substituted by an Ile (I), whereas in Glyma11g28880.1 (GmbZIP75), the conserved Arg/Lys (R/K) in the basic region was substituted by a $\operatorname{Trp}(\mathrm{W})$. In C. Cajan19144 (CcbZIP24), the heptad repeat of Leu was positioned at 23 amino acids toward the $\mathrm{C}$ terminus instead of the usual nine. All of these unusual changes in the bZIP domain have been observed in rice bZIP sequences previously $[5,54]$.

\section{Phylogenetic analysis and classification of legume bZIP genes}

To investigate the phylogenetic relationships of the bZIP transcription factors, 585 protein sequences from the six legumes and 71 protein sequences from Arabidopsis (three genes were no longer supported by their updated annotations) [4] were analyzed (Fig. 1 and Additional file 3). In accordance with the bZIP classification in Arabidopsis [4], the phylogenetic tree was subdivided into 10 clades with well-supported bootstrap values. All groups contained legume bZIP proteins clustered together with AtbZIP proteins in the same clade, except group F, which included members from only three genomes: G. max, $P$. vulgaris and $C$. arietinum. In addition, 15 legume bZIP proteins and 3 AtbZIP genes (AtbZIP60, AtbZIP62 and AtbZIP72) formed two small unique and several other individual clades (bold black branch in Fig. 1), which were classified into the unclassified group (group $\mathrm{U}$ ) based on their possible independent evolutionary trajectories from other clades. Group classification was supported by the groupspecific sequence characteristics identified in the following analyses of gene structures, intron phases, additional conserved motifs outside the bZIP domain and DNA-binding site specificity in each group. It is evident that the group-specific sequence characteristics of the bZIP members formed before the divergence of Arabidopsis and legumes since conserved sequence characteristics were present in the same group containing both Arabidopsis and legumes bZIP genes. Nevertheless, it seems that intra-species duplication and parallel evolution of the bZIP family in each legume has occurred afterward and contributed to the member variation in each group.

\section{Gene structure of legume bZIP genes}

The intron-exon organization can reflect the evolutionary trajectory of gene families $[5,7,55,56]$. We examined the gene structures of all 585 legume bZIPs and found that the structural patterns were similar among members within each group but distinct between different groups (Additional file 4). The number of introns in each group was uneven but relatively concentrated (Additional file 5). We detected 29 GmbZIP genes (12.03\%), 15 MtbZIP genes (15.15\%), 16 PvbZIP genes (17.39\%), 12 CabZIP genes (20.34\%), 13 CcbZIP genes (21.31\%) and 9 LjbZIP genes $(27.27 \%)$ with no introns. Most of these intronless genes were clustered into groups S and F (Additional files 3 and 4). Among the intron-containing $b Z I P$ genes, the number of introns within the open reading frame (ORF) varied from 1 to 11 in GmbZIP, 15 in MtbZIP, 11 in PvbZIP, 11 in Cab$Z I P, 11$ in CcbZIP, and 8 in LjbZIP, close to the highest number of introns within the ORF reported in Arabidopsis (12) [4], rice (12) [5], sorghum (14) [6], maize (14) [7], castor bean (11) [10], barely (11) [11] and cucumber (12) [9]. The bZIP genes with the most introns were commonly found in groups D and G (Additional file 4).

The intron positions within the ORF were diverse. The phases of the splicing sites within the ORFs also differed, but the positions and phases of introns in the basic and hinge regions of the bZIP domain were highly conserved. The legume bZIP genes showed four intron patterns $(\mathrm{a}-\mathrm{d})$ based on the intron positions, presence or number and splicing phases within the basic and hinge regions (Fig. 2 and Additional file 2). Pattern a, having one intron in phase 0 ( $\mathrm{PO}$ indicates the intron splicing site is between codons) within the hinge region at the -5 position, was seen in all members of groups $A$ and $G$ in the legumes. Pattern b, having two introns each in phase 0 : one in the basic region at the -25 position and the other in the hinge region at the -5 position, was seen in all members of group D in the legumes. Pattern c, having a single intron in phase 2 (P2 means the intron splicing site is located between the second and third nucleotides of one codon) at the -20 position in the basic region, was seen in all members of groups $\mathrm{C}, \mathrm{E}$ and $\mathrm{H}$ in the legumes. Pattern $\mathrm{c}$ also was seen in all members of group I in G. max, M. truncatula, C. arietinum and C. cajan, and most members (3/5) of group I in L. japonicus. Pattern $\mathrm{d}$ was no introns in the basic and hinge regions and was seen in groups $\mathrm{B}, \mathrm{S}$ and $\mathrm{F}$, which contained most of the intronless genes. Among 106 genes showing pattern d, 85 were intronless, while the remaining 22 had introns outside the basic and hinge regions. In summary, the overall pattern of intron position acts as an index for the group classification and phylogenetic relationships in the legume bZIP gene 


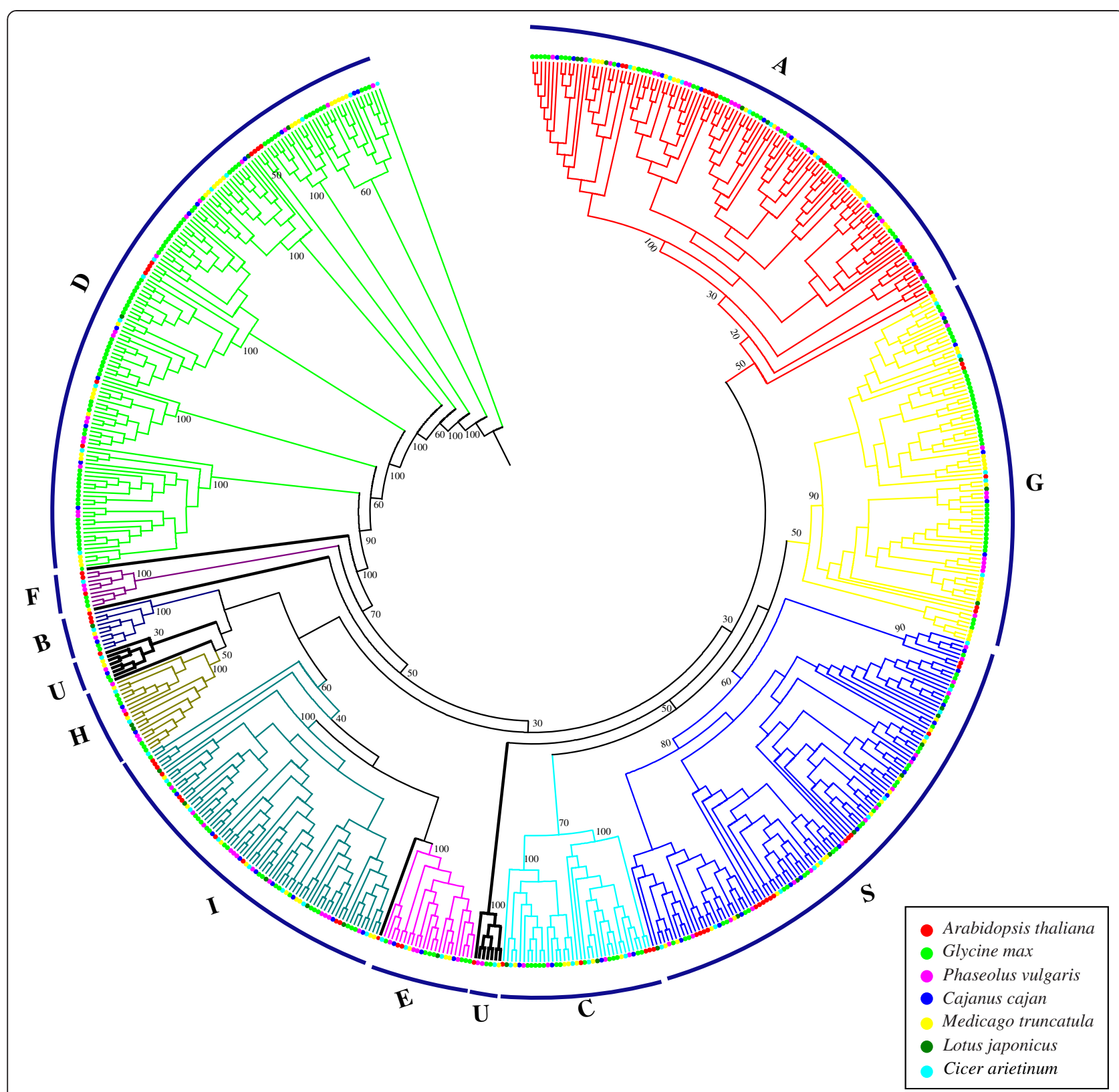

Fig. 1 Phylogenetic tree of legume and Arabidopsis bZIP genes. bZIP protein sequences were aligned by Clustal X and the phylogenetic tree was constructed using PhyML by the maximum likelihood method. Bootstrap values are based on 100 replicates. Genes on branch ends from different species are denoted by different colored circles. The legume bZIP proteins were grouped into 11 distinct clades $(A-I, S, U)$, which are indicated by colored branches

family. The splicing phase has remained well conserved during the course of evolution in legume bZIP genes.

\section{Identification of additional structural features in the legume bZIP genes}

All legume bZIP protein sequences were loaded into the MEME analysis tool and a total of 50 additional conserved motifs outside the bZIP domain were identified. The multi-level consensus sequences and the amino acid lengths of these conserved motifs are given in Additional file 6. The legume bZIP proteins within the same group had similar motif compositions, suggesting conserved evolution and supporting the group classification (Fig. 3). Additionally, some motifs were shared by different groups, such as motifs 46 and 47 in two groups, motif 14 in three groups, motifs 17 and 50 in four groups, and motifs 5,12 and 43 in five groups. Nevertheless, most of the conserved motifs appeared specific to each group (Additional file 6) and therefore the group-specific motifs could help determine the specific functions of 


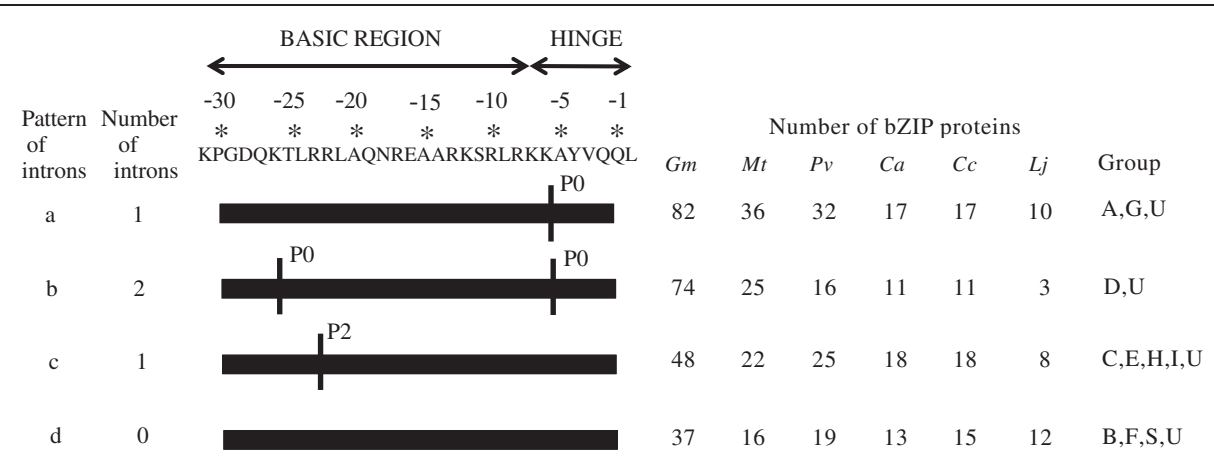

Fig. 2 Intron patterns within the basic and hinge regions of the legume bZIP domain. The primary structure of the bZIP domain is shown at the top of the picture. P0 indicates the intron splicing site is between codons, and P2 means the intron splicing site is located between the second and third nucleotides of one codon. Based on the intron incidence and positions, as well as the splicing phase, the legume bZIP genes were divided into four patterns $(a-d)$. Details of the intron positions within the bZIP domain in the legume bZIP proteins are shown in Additional file 2

members in each group. Notably, we did not detect any additional conserved motifs outside the bZIP domain in groups $\mathrm{B}$ or $\mathrm{F}$.

A few of these motifs in legume bZIPs have been studied for their possible biological functions. A part of motifs 7, 10 and 11 represent potential casein kinase II (CK II) phosphorylation sites $(\mathrm{S} / \mathrm{TxxD} / \mathrm{E})$, indicated by the motif patterns [TS][AV]E[AE], TLGE(TLED) and TVDE. Motif 11 also contained a phosphorylation site for the $\mathrm{Ca}^{2+}$-dependent protein kinase $(\mathrm{R} / \mathrm{KxxS} / \mathrm{T})$, presented as RQ[GA]S. Motif 31 in group $H$ was group-specific, and contained potential CK II phosphorylation sites (S/ TxxD/E), indicated by [SP]CYE. Such motifs were identified in group A exclusively. In addition, all members in group D shared motif 1, which was a DOG1 domain, and motif 4, the function of which was unclear (Additional file 6). Motifs 9, 22 and 29 were observed in group $G$ exclusively and were characterized by a part of the proline-rich domain, which has been shown to have transcriptional activation potential. Interestingly, there were some common motifs among the six legumes, maize and rice $[5,7]$. For example, motif 11 in group $\mathrm{A}$ was the same as motif 18 in group A in maize. Motifs 1 , 2 and 3 in group D are in common with motifs 1,2 and 5 in group D of maize and motifs 18, 20 and 19 of rice, respectively.

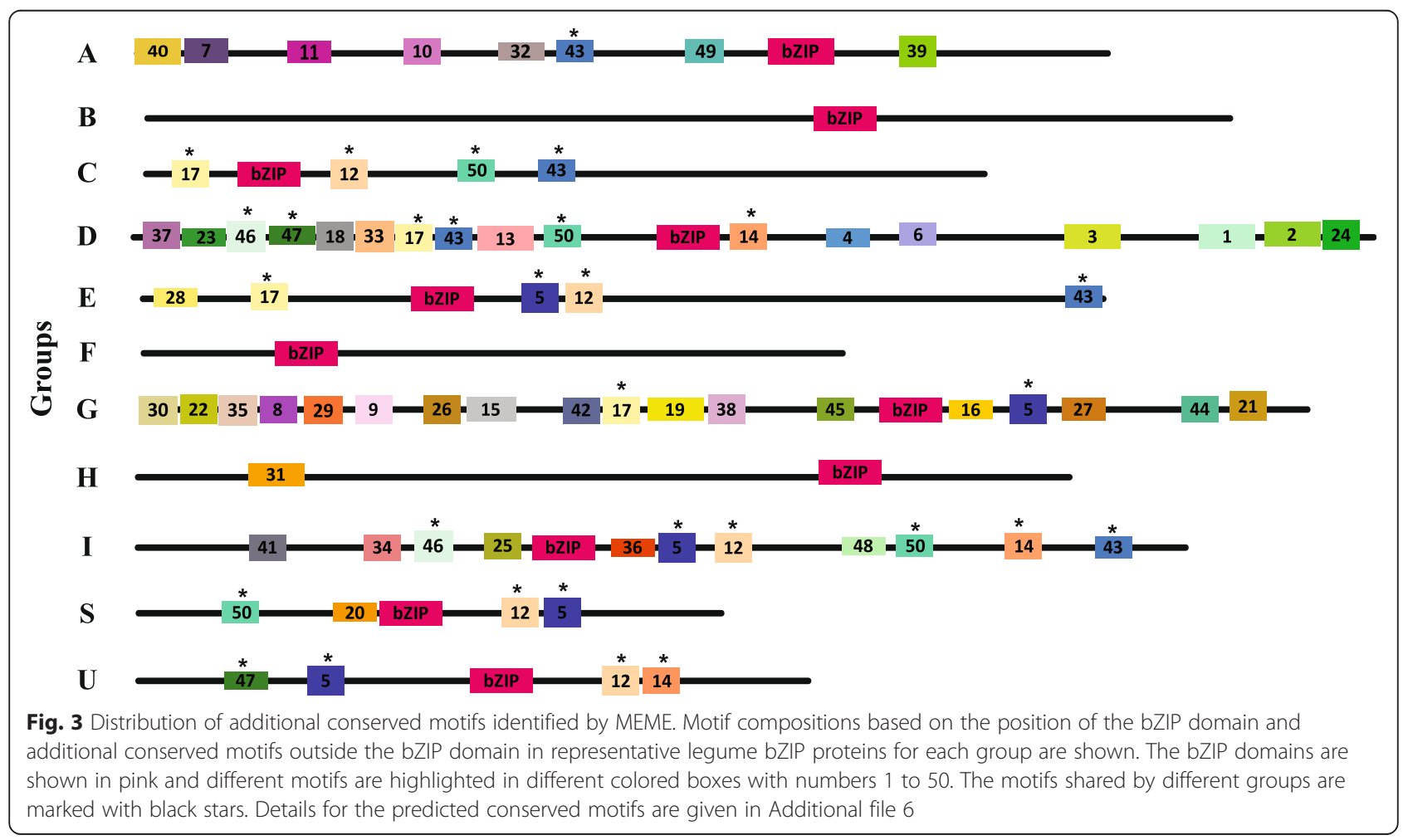




\section{Prediction of DNA-binding-site specificity in legume bZIP proteins}

Experiments of mutant proteins demonstrated that the bZIP TFs binding specificity is independently determined by the core basic region and the hinge region, and the two regions have an additive effect on DNAbinding specificity $[57,58]$. To predict the DNAbinding-site specificity of the legume bZIP proteins, the amino acid sequences of the basic and hinge regions of 585 legume bZIP proteins were aligned, revealing some highly conserved amino acid residues within each group (Additional file 7). We can predict the DNA-binding specificity in a group manner, as described in Additional file 8 . Furthermore, the amino acids were numbered as previously reported $[5,7,59]$, and the first Leu in the Leu heptad repeats was numbered +1 . For the two invariant sites asparagine $(\mathrm{Asn} / \mathrm{N})$ and arginine $(\mathrm{Arg} / \mathrm{R})$, numbered -18 and -10 , respectively, new DNA-binding specificities will occur if other amino acids functionally replace these two invariant sites ( $\mathrm{N}$ and $\mathrm{R}$ ) [57]. Nevertheless, such replacements were infrequent and occurred only in groups $\mathrm{G}$ and $\mathrm{U}$ in the legume bZIP proteins. At position -18 , the conserved asparagine $(\mathrm{N})$ was replaced with lysine (K) in GmbZIP80 and PvbZIP67 in group G (Additional file 7). The same replacement (from $\mathrm{N}$ to $\mathrm{K}$ ) was also observed in four bZIPs in maize [7], two bZIPs in barley [11], and two bZIPs in castor bean [10]. At position -10 , nine members in group $U$ had a hydrophobic isoleucine (Ile/I) residue instead of arginine (R) or lysine (K). An identical substitution pattern (from $R / K$ to I) was observed in two bZIPs in maize [7], two in barley [11], one bZIP in grapevine [8], and one bZIP in castor bean [10]. It was demonstrated that an arginine to isoleucine mutation in the basic domain of the yeast bZIP factor GCN4 completely inhibited its affinity for the AP1 site [57]. Additionally, it was reported that OsZIP2 a belonging to group $U$ in rice, because of this replacement, does not recognize G-boxes [54]. This evidence suggests that unusual substitutions in the DNA-binding domain affect the DNA-binding specificity. These predictions were made to facilitate further studies on the DNA-binding patterns of the legume bZIP transcription factors.

\section{Prediction of dimerization properties in legume bZIP proteins}

Studies have demonstrated that the Leu zipper region of the bZIP domain, arranged in the form of heptad repeats, mediates homo- and/or heterodimerization between the parallel coiled-coil structures [60-62]. Within each heptad, the amino acid positions are recognized in order as $g, a, b, c, d, e$, and $f[63,64]$ (Additional file 9). Leu zipper oligomerization, dimerization stability and specificity are determined mainly by the four amino acids present at the $a, d, e$ and $g$ positions because of their special positions near the Leu zipper interface. The $a$ and $d$ residues are typically hydrophobic on the surface of the helix and create a hydrophobic core that promotes the interaction between two monomers and is essential for dimer stability [65]. The $a$ position contains asparagine $(\mathrm{Asn} / \mathrm{N})$, which can form a polar pocket in the hydrophobic interface that limits oligomerization in interhelical interactions [66] and produce more stable $\mathrm{N}-\mathrm{N}$ interactions at $a \leftrightarrow a^{\prime}$ (the corresponding position in the opposite helix) than other amino acids [64]. The conserved Leu at the $d$ position, one of the most stabilizing aliphatic amino acids [67], is important to maintain dimer stability. However, the $e$ and $g$ positions that flank the dimerization interface frequently contain charged amino acids including the acidic amino acids glutamic acid (E) and aspartic acid (D), and the basic amino acids arginine (R) and lysine (K), which are thought to form salt bridges between helices in electrostatic interactions [68].

To predict the dimerization properties of the legume bZIP transcription factors, a detailed analysis was carried out to characterize the amino acids present at the $a, d, e$ and $g$ positions (Additional file 9). Figure 4a shows the composition of different kinds of amino acids found in the $a, d, e$ and $g$ positions in the six legume bZIPs, respectively. At the $a$ position, about $25 \%$ of the residues were asparagine $(A s n / N)$, suggesting that there will be a greater number of homodimerizing Leu zippers through stable $\mathrm{N}-\mathrm{N}$ interhelical interaction at the $a \leftrightarrow a^{\prime}$ position among legume bZIP proteins. The frequency of asparagine $(\mathrm{Asn} / \mathrm{N})$ residues in the $a$ position was highest in the second heptad followed by the fifth heptad, accounting for $57.51 \%$ and $47.45 \%$, respectively (Fig. 4b), similar to earlier observations for AtbZIP proteins [64]. At the $d$ position, the frequency of Leu, responsible for dimer stability, was about $68 \%$ in the legume bZIPs (Fig. 4a), which is a little less than in OsbZIPs (71 \%) [5] and ZmbZIPs (70 \%) [7], but significantly greater than in AtbZIPs (56 \%) [64]. At the $e$ and $g$ positions (Fig. 4a), the frequencies of charged amino acids (including acidic amino acids $\mathrm{D}$ and $\mathrm{E}$, and basic amino acids $\mathrm{R}$ and $\mathrm{K}$ ) were 49 and $59 \%$, respectively.

In electrostatic interactions, the amino acids at position $g$ and oppositely charged amino acids at position $e^{\prime}$ (the prime means a residue on the opposite helix of the leucine zipper) can form interhelical salt bridges that determine the dimerization specificity and stability [68]. The dimerization specificity of human, Drosophila, Arabidopsis, rice, maize, barley and castor bean bZIP TFs has been predicted on the basis of attractive or repulsive interhelical $g \leftrightarrow e^{\prime}$ electrostatic interactions [5, 7, $10,11,64,69,70]$. To analyze the contribution of charged residues to the dimerization properties of the legume bZIP proteins, we calculated the frequency of 


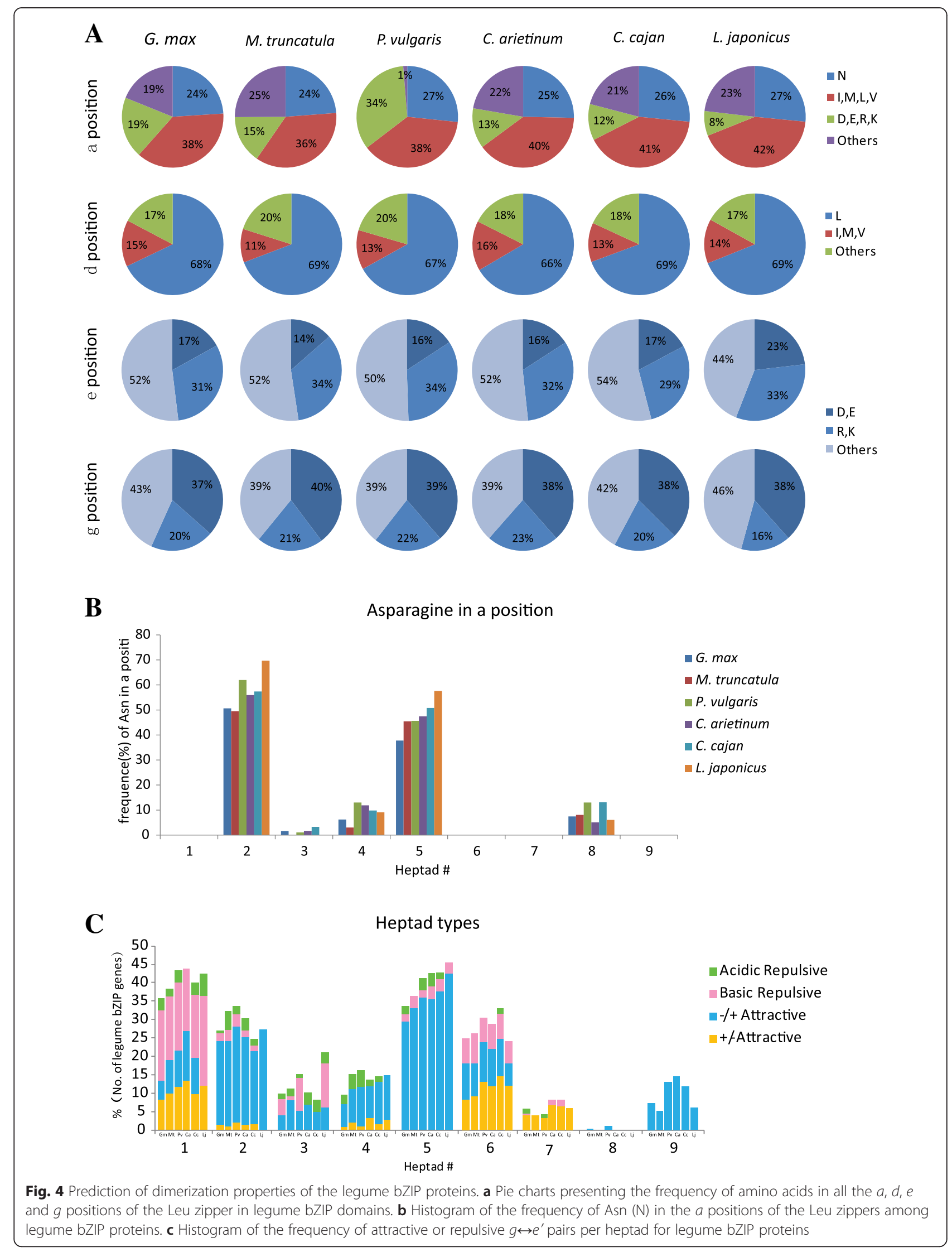


attractive and repulsive $g \leftrightarrow e^{\prime}$ pairs in each heptad of the bZIP Leu zippers; the corresponding histograms are shown in Fig. 4c. If both the $g$ and corresponding $e$ position amino acids are charged, they are referred to as complete $g \leftrightarrow e^{\prime}$ pairs. This analysis was carried out on the basis of the frequency of attractive and repulsive $g \leftrightarrow e^{\prime}$ pairs, which were classified into four groups, attractive basic-acidic pairs (+/-attractive), attractive acidic-basic pairs (-/+ attractive), repulsive basic pairs (basic repulsive) and repulsive acidic pairs (acidic repulsive) in the heptads. Attractive $g \leftrightarrow e^{\prime}$ pairs were predominant in the second, fifth and sixth heptads, thereby suggesting the chances of heterodimerization (Fig. 4c). In contrast, few complete $g \leftrightarrow e^{\prime}$ pairs were observed in the eighth heptads except two attractive acidic-basic $(-/+$ attractive) pairs from GmbZIP102 and PvbZIP4 (Additional file 9). Moreover, only attractive acidic-basic (-/+ attractive) pairs were present in ninth heptads (Fig. 4c), which was similar to observations in HvbZIPs [11], OsbZIPs [5] and ZmbZIPs [7].

We divided the 585 legume bZIP proteins into 44 subfamilies (BZ1-BZ44) on the basis of the defining properties of dimerization specificity $[64,70]$. These subfamilies were divided into three general groups: (i) those that strongly favor homodimerization within eight subfamilies (BZ1-BZ8), (ii) those with both homo- and heterodimerization properties (BZ9-BZ39) and (iii) those that strongly favor heterodimerization within five subfamilies (BZ40BZ44). The results indicated the complexity and diversity of dimerization patterns in legume bZIP proteins, with the potential to homodimerize with themselves or with members in the same subfamily as well as heterodimerize with other subfamily members, which has been shown in maize [7], rice [5], and Arabidopsis [64]. Based on the criteria used to define the boundaries and natural C-terminus, we observed that the length of the Leu zipper in the bZIP transcription factor family was variable, ranging from two to nine heptads. Among the bZIP proteins, $2.39 \%$ had only two short zippers and belonged to BZ43 and group G, about $28 \%$ had only three short zippers (mainly in BZ40-BZ42 and groups D and E), and about $9 \%$ had no $\alpha$-helix breakers for 10 or more heptads, were mainly distributed in BZ37-BZ39 and included members of group I.

\section{The impact of whole genome duplication and tandem duplication on the expansion of the legume bZIP gene family}

To explore the expansion mechanism in detail, we analyzed the contribution of WGD -derived segmental duplication and tandem duplication to the expansion of the legume bZIP gene family. First, a phylogenetic tree was constructed based on the concentrated orthologous sequences of $r b c$ and matk genes from the six legume genomes, which supported the classification of two sub-clades of Papilionoideae legumes: Phaseoloids (clade I, including $G m, C c$ and $P v$ ) and Hologalegina (clade II, including $M t, C a$ and $L j$ ) (Fig. 5a). We carried out a genome-wide identification of collinear duplicated blocks derived from segmental duplication in each species, and then examined the pairwise synonymous distances (Ks values) of paralogs within duplicated collinear blocks. By plotting their distribution, two distinct peaks were found (Fig. 5 b: Ks bin =0.1): one was specific to $G m-G m$ paralogues, while the other was observed in all six legumes.

Second, the chromosomal distribution of the legume bZIP genes was plotted and the bZIP gene pairs on duplicated chromosomal collinear segments were connected by lines (Fig. 5c, d, Additional files 10 and 11). Among these genes, some were segmentally duplicated once and some were duplicated twice or thrice. The duplication occurred within a chromosome or between chromosomes. We detected $119 \mathrm{Gm}, 24 \mathrm{Mt}, 38 \mathrm{Pv}, 30$ $\mathrm{Ca}, 8 \mathrm{Cc}$ and $2 \mathrm{Lj}$ bZIP genes involved in segmental duplication, accounting for around $86.2 \%(119 / 138, \mathrm{Gm})$, $36.9 \%(24 / 65, M t), 52.8 \%(38 / 72, P v), 50.8 \%(30 / 59$, $\mathrm{Ca}), 13.1 \%(8 / 61, C c)$, and $6.1 \%(2 / 33, L j)$ of the bZIP genes in each species. The higher ratio in soybean reflects the preferential gene retention after multiple rounds of WGD, while the different ratios among the other five legumes may be mainly attributable to the genome assembly quality (for example, relatively incomplete in $C c$ and $L j$ ) or species-specific evolution in each genome.

Moreover, we roughly identified different WGD event origins for duplicated bZIP gene pairs according to their pairwise synonymous distances using criteria from soybean [12]: Ks values of $0.06-0.39$ correspond to the 13Mya Glycine-lineage-specific WGD, and Ks values of $0.40-0.80$ in soybean and $0-1.00$ in the other five legumes correspond to the 59-Mya early-legume WGD, while larger Ks values correspond to more ancient WGD events like the 'gamma' event [14]. By ordering the Ks values, 55 Gm bZIP gene pairs were associated with the 13 Mya Glycine-lineage-specific WGD and $28 \mathrm{Gm}, 4 \mathrm{Mt}, 8 \mathrm{Pv}, 6 \mathrm{Ca}, 2$ $C c$, and $0 L j$ bZIP gene pairs were associated with the 59 Mya early-legume WGD; the others were associated with more ancient WGDs (Additional file 11). Because only soybean has undergone the Glycine-lineage-specific WGD, the other five legume genomes could be considered putative ancestors for investigating gene retention and loss after the recent genome duplication in soybean. $M t$ and $P v$ were chosen, because of their good genome assembly and annotation, to construct phylogenetic trees with $\mathrm{Gm}$ genes. We identified informative tree models of gene retention: $[P v,(G m, G m)]$ and $[M t,(G m, G m)]$, and gene loss $[(P v, G m)]$ and $[(M t, G m)]$, showing that $83 \%(P v$ as outgroup) and $87 \%$ ( $M t$ as outgroup) ancestral loci were retained as paralogs in soybean after the recent WGD 
$\mathbf{A}$

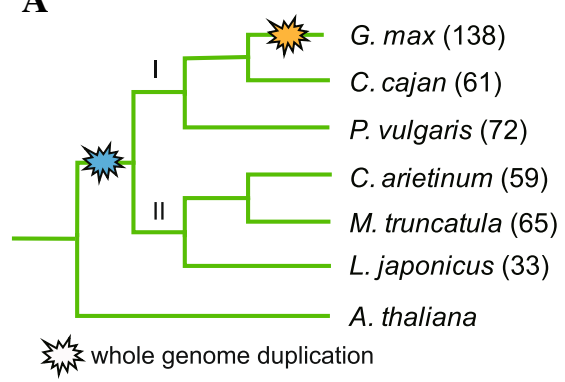

C

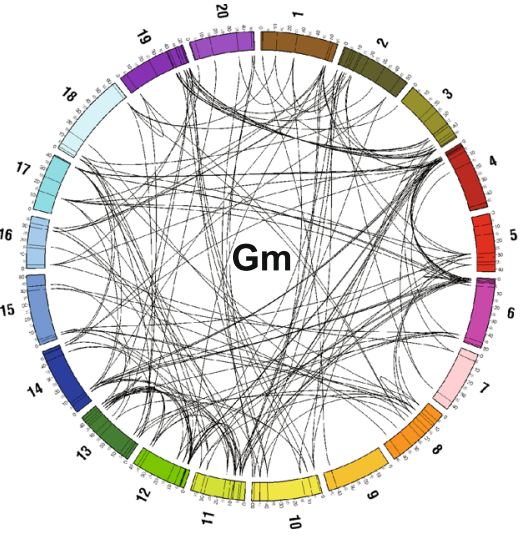

$\mathbf{E}$

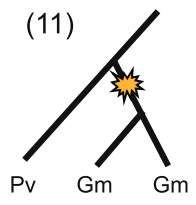

(6)

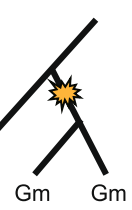

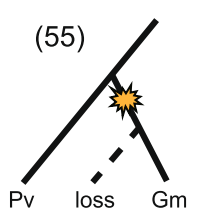

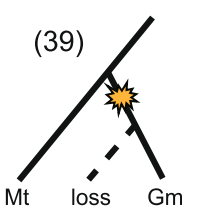

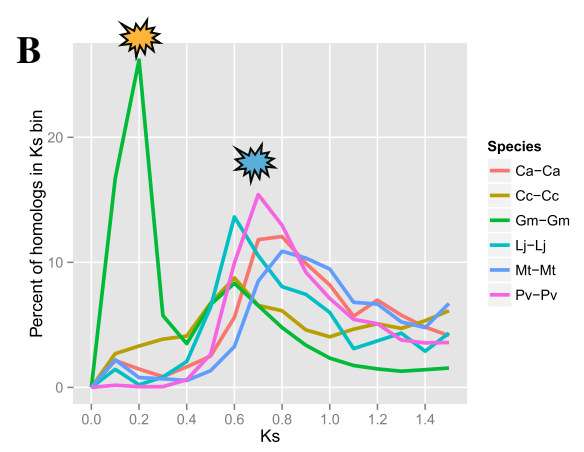

D

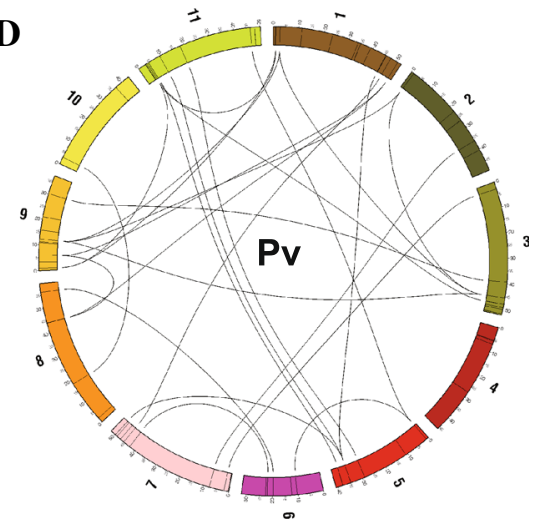

$\mathbf{F}$

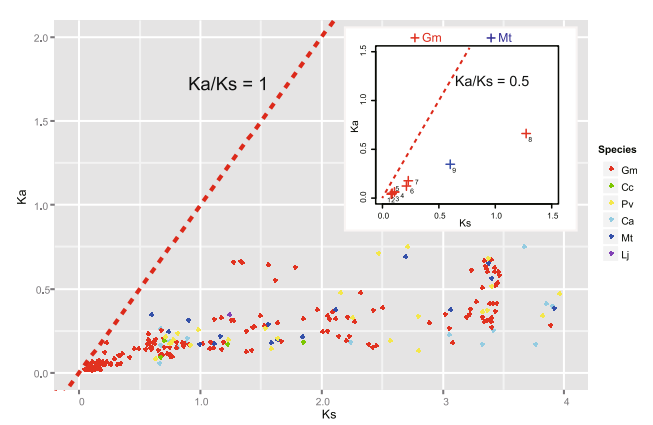

Fig. 5 Whole genome duplication (WGD)-derived legume bZIPs genes. a The phylogenetic relationships of the six legumes based on the concentrated orthologous sequences of rbc and matk genes. Two WGD events, the Glycine-lineage-specific and early-legume WGD events, are indicated on the corresponding clades. $\mathbf{b}$ The Ks distribution of paralogs derived from WGD-derived duplicated genomic blocks in each legume. Two obvious peaks correspond to the old and recent legume-lineage WGD events. c, $\mathbf{d}$ The black lines in the ideogram show the chromosomal positions of all identified bZIP genes, and the duplicated bZIP pairs are linked by lines in soybean (c) and common bean (d). e Patterns of gene retention or loss indicated by two different informative tree topologies using common bean and Medicago as outgroups, respectively. The numbers for each pattern are shown in parentheses. $\mathbf{f}$ The Ks (x-axis) and Ka ( $y$-axis) distribution for each duplicated legume bZIP gene pair. The red dashed line means the Ka/Ks ratio is equal to 1. Particularly, eight Gm duplicated pairs (red cross) and one Mt pair (blue cross), whose Ka/Ks values were greater than 0.5 , are indicated in the inner figure (under the dashed line of $\mathrm{Ka} / \mathrm{Ks}=0.5$ ). The red dashed line in inner figure means the $\mathrm{Ka} / \mathrm{Ks}$ ratio is equal to 0.5. The numbers (1-9) correspond to duplicated pairs: 1: GmbZIP23-GmbZIP131; 2: GmbZIP49-GmbZIP109; 3: GmbZIP55-GmbZIP107; 4: GmbZIP8-GmbZIP113; 5: GmbZIP4-GmbZIP69; 6: GmbZIP26-GmbZIP42; 7: GmbZIP87-GmbZIP101; 8: GmbZIP65-GmbZIP113; 9: MtbZIP2-MtbZIP26

(Fig. 5e). Compared with the average $43.4 \%$ of genes retained as paralogs at the whole genome level [12], genes of the bZIP family were highly retained.

To better understand the evolutionary constraints acting on the legume bZIP genes, we calculated the Ka/Ks ratios for all legume duplicated bZIP gene pairs. The resulting pairwise comparison data showed that the $\mathrm{Ka} / \mathrm{Ks}$ values of only eight $G m$ duplicated pairs and one $M t$ pair were larger than 0.5 (but less than 1) while all of the remaining $\mathrm{Ka} / \mathrm{Ks}$ ratios were less than 0.5 (Fig. $5 f$ and Additional file 11), suggesting that the bZIP family has mainly undergone strong purifying selection and the legume bZIP genes are slowly evolving at the protein level. We further compared the strength of selection on bZIP 
paralogs between the recent and old whole-genome duplications in soybean. The average Ka/Ks ratio for the recently duplicated bZIP genes (0.305) was higher than that of the early duplicated bZIP genes (0.249), and there was a significant difference between these ratios ( $\mathrm{t}$-test, $P=0.025)$. This indicated that the younger bZIP proteins may be under stronger evolutionary constraints than older proteins, but supported the notion that the legume bZIP gene family is essential for the regulation of cellular processes.

Third, we determined members with tandem duplication in each legume (highlighted in red in Additional file 10). We detected only $1 \mathrm{Gm}, 3 \mathrm{Mt}, 0 \mathrm{Pv}, 0 \mathrm{Ca}, 0 \mathrm{Cc}$ and $0 \mathrm{Lj}$ tandem gene pairs, indicating the limited contribution of tandem duplication to the expansion of the gene family. Therefore, it seems that segmental duplication rather than tandem duplication is the major mechanism driving the expansion of this gene family.

\section{Expression analysis of bZIP transcription factors}

Expression data from different tissues (nodule, root, stem, leaf, flower, and pod) and seed developmental stages in soybean [47], Medicago [49, 50], common bean [48] and Lotus [51] were downloaded, and hierarchical clustering was performed to visualize a global transcription profile of the legume bZIP genes. As shown in Fig. 6 (a: $G m$, b: $P v, \mathrm{c}: M t, \mathrm{~d}: L j$ ), the heatmaps were always divided into three recognized clusters, which was similar to the results in rice [5], maize [7] and other plants [8, 11]. The different clusters corresponded to overall differences in expression patterns including expression values and specificity across tissues. The latter was indicated by $\mathrm{CV}$ values (coefficient of variation), which were calculated for each gene, and helped to recognize genes expressed in specific tissues or stages (Additional file 12). Cluster I included genes with relatively high expression levels and the least expression variability (lower $\mathrm{CV}$ values), indicating an extensive and stable expression pattern relative to the other legume bZIP genes. Cluster II included genes with variable and moderate expression. Cluster III included genes with inconsistent (always higher $\mathrm{CV}$ values) but low expression in tissues. The broad expression pattern across various tissues indicated that members of the legume bZIP transcription factor family are either expressed constitutively or in an organspecific, development-dependent manner and may be involved in organ and tissue differentiation and seed developmental processes. Among the genes that were highly expressed during seed developmental stages, some were identified as homologs/orthologs of well-studied bZIP genes from Arabidopsis [4], rice [5] and maize [7]. The AtbZIP39/ABI5 gene, a homolog of MtbZIP53, PvbZIP10 and PvbZIP33 (extracted expression values are shown in Fig. 6), is functionally involved in ABA signaling and mediating embryogenesis in late embryo development
[71]. AtbZIP66/AREB3/DPBF3 and AtbZIP67/DPBF2, which were homologs of PvbZIP71, LjbZIP29 and LjbZIP14, have been confirmed to play important roles in ABA-mediated seed development, germination, and embryo maturation [72]. In addition, GmbZIP63 and MtbZIP55 were homologous to the maize bZIP factor Opaque2, which controls the transcription of $a$-zein, $b$ 32 and b-prolamin genes and regulates protein accumulation, and amino acid and sugar metabolism in maize seeds [73-76].

As a kind of ubiquitous transcription factor, bZIP proteins regulate the expression of a wide spectrum of stress-related genes. We analyzed the expression values measured in drought-stressed roots and shoots corresponding to $3,4,7,10$, and 14 days of drought, and in salt-stressed roots upon $180 \mathrm{mM} \mathrm{NaCl}$ treatment. We identified the obvious up- and down-regulated genes (at least 2 -fold, with a $P$-value $<0.05$ ) and the $\log 2$ (treated/ control) ratio values were illustrated by heatmaps (Fig. 6e, f). We detected five genes (MtbZIP53_A, MtbZIP62_G, MtbZIP58_S, MtbZIP24_I, and MtbZIP60_D) upregulated both in roots and shoots under drought stress, one gene (MtbZIP59_G) up-regulated only in roots, and three genes (MtbZIP35_A, MtbZIP46_S, and MtbZIP2_S) up-regulated only in shoots. Among the genes down-regulated under drought stress, MtbZIP18_I, MtbZIP41_A and MtbZIP34_A were down-regulated in both roots and shoots, MtbZIP56_C was only downregulated in roots, and MtbZIP30_D was only downregulated in shoots. In roots under salt stress, MtbZIP60_D, MtbZIP32_I, MtbZIP26_S, MtbZIP2_S and MtbZIP4_I were up-regulated and MtbZIP54_S, MtbZIP34_A and MtbZIP28_S down-regulated. Most of the genes showing a response to drought and salt stress were concentrated in groups A and S. bZIP genes from these groups have been frequently reported to be involved in sugar signaling and abiotic stress regulation $[4,77,78]$. Notably, the CKII and $\mathrm{Ca}^{2}$ ${ }^{+}$-dependent protein kinase phosphorylation site motifs (motifs 7, 10 and 11) confined to group A in this study have been proposed to be involved in stress and/or ABA signaling, which plays an important the role in the adaptation of plants to various abiotic environmental stress conditions like drought, high salinity, and cold stress [79]. ABI5 (ABA insensitive 5) and ABFs (ABRE binding factors)/AREB (ABA-responsive element binding protein) have been shown to be key ABAdependent signal transduction factors involved in abiotic stress tolerance [22, 80]. Among the stressresponsive legume bZIP genes (Fig. 6e, f), MtbZIP53 and MtbZIP34 were homologous to ABI5 and ABFs/ AREB, respectively. In addition, two genes, MtbZIP2 and MtbZIP26, were responsive to salt stress and homologous to AtbZIP1, which has been reported to be 


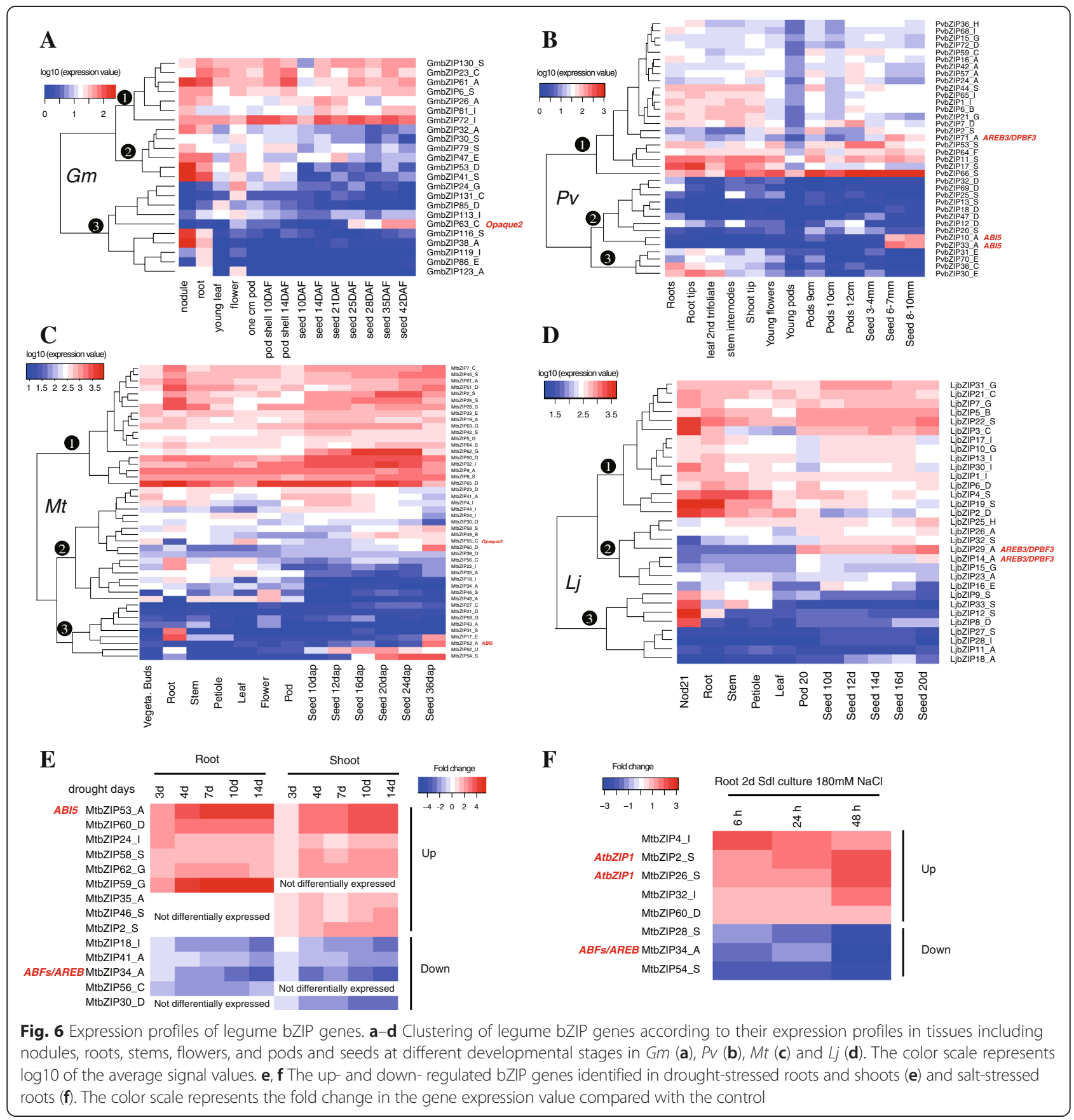

transcriptionally induced by salt treatment $[81,82]$ and leads to enhanced or reduced tolerance to salt stress when overexpressed or knocked out, respectively [83]. Overall, the expression analysis presented here improves our understanding of plant responses to stress at the molecular level and provides candidate legume bZIP genes for future research.

\section{Conclusions}

bZIP transcription factors have been extensively characterized in eukaryotic genomes and have been shown to play crucial roles in plant development, physiological processes, and biotic/abiotic stress responses. Using the six legume genomes available, we performed an extensive study of legume bZIP genes including structure, phylogeny, sequence, and expression analyses. The group classification of legume bZIP genes based on their phylogenetic relationships was supported by subsequent analyses of gene structure, intron phases in the bZIP domain, MEME motif composition, DNA-binding specificity and dimerization patterns, which showed groupspecificity. The group-specific sequence characteristics 
of the bZIP members should have formed before the divergence of Arabidopsis and legumes since conserved sequence characteristics were present in the same group containing both Arabidopsis and legume bZIP genes. The global expression profile supports the role of legume bZIP proteins in performing diverse developmental and physiological functions during tissue differentiation and seed development, as well as drought and salt stresses.

\section{Availability of supporting data}

The data set supporting the results of this article is available in the Dryad Digital Repository, http://dx.doi.org/ 10.5061/dryad.m0qc8.

\section{Additional files}

Additional file 1: The identified legume bZIP proteins and their related information. (XLS $173 \mathrm{~kb}$ )

Additional file 2: Position and pattern of introns within the basic and hinge regions of bZIP domains of the legume bZIP transcription factors. (PDF $1398 \mathrm{~kb}$ )

Additional file 3: The phylogenetic analysis of bZIP proteins based on the bZIP protein sequences from Arabidopsis (71 bZIP proteins) and six legumes (585 bZIP proteins) corresponding to Fig. 1. (PDF 1003 kb)

Additional file 4: The map of intron-exon arrangement of legume bZIP genes. (PDF $1488 \mathrm{~kb}$ )

Additional file 5: Histogram of intron number of legume bZIP genes in each group. (PDF $410 \mathrm{~kb}$ )

Additional file 6: The detailed information of additional conserved motifs in bZIP proteins as predicted by MEME. (XLS $176 \mathrm{~kb}$ )

Additional file 7: Alignment of basic and hinge regions of $\mathbf{5 8 5}$ legume bZIP proteins. (PDF $1687 \mathrm{~kb}$ )

Additional file 8: DNA binding specificity prediction of each group. (DOC $51 \mathrm{~kb}$ )

Additional file 9: Amino acid sequence alignment of the leucine zipper region of $\mathbf{5 8 5}$ legume bZIP proteins. (PDF $4254 \mathrm{~kb}$ )

Additional file 10: Chromosomal distributions of legume bZIP genes. (PDF $2418 \mathrm{~kb}$ )

Additional file 11: bZIP genes present on duplicated chromosomal segments. (XLS $68 \mathrm{~kb}$ )

Additional file 12: Expression values of legume bZIPs in multiple tissues. (XLS $76 \mathrm{~kb}$ )

\section{Abbreviations}

WGD: Whole genome duplication; Mya: Million years ago; HMM: Hidden Markov model; ML: Maximum likelihood; ORF: Open reading frame; MEME: Multiple expectation maximization for motif elicitation; $A B$ I5: ABA-insensitive 5; ABRE: ABA response element; $A B F$ : ABRE binding factor; AREB: ABA-responsive element binding protein.

\section{Competing interests}

The authors declare that they have no competing interests.

\section{Authors' contributions}

$Z W, Y L$ and $B L$ conceived and designed the experiments, ZW, KC, LW, LY, HJ, $S L, Y L$ and $B L$ analyzed the data, $Z W, Y L$ and $B L$ wrote the paper. All authors have read and approved the final version of the manuscript.

\section{Acknowledgements}

This research was supported by the National Natural Science Foundation of China (nos. 31461143022, 31301256, 31071456 and 31471536), National High Technology Research and Development Program of China (863 Program, no. 2013AA102602), National Basic Research and Development Program (973 Program, nos. 2011 CB109304 and 2011CB109305).

Received: 7 August 2015 Accepted: 30 November 2015

Published online: 10 December 2015

\section{References}

1. Mitchell PJ, Tjian R. Transcriptional regulation in mammalian cells by sequence-specific DNA binding proteins. Science. 1989;245(4916):371-8.

2. Ptashne M, Gann A. Transcriptional activation by recruitment. Nature. 1997;386(6625):569-77.

3. Hurst HC. Transcription factors 1: bZIP proteins. Protein Profile. 1995;2(2):101-68.

4. Jakoby M, Weisshaar B, Droge-Laser W, Vicente-Carbajosa J, Tiedemann J, Kroj T, et al. bZIP transcription factors in Arabidopsis. Trends Plant Sci. 2002;7(3):106-11.

5. Nijhawan A, Jain M, Tyagi AK, Khurana JP. Genomic survey and gene expression analysis of the basic leucine zipper transcription factor family in rice. Plant Physiol. 2008;146(2):333-50.

6. Wang J, Zhou J, Zhang B, Vanitha J, Ramachandran S, Jiang SY. Genome-wide expansion and expression divergence of the basic leucine zipper transcription factors in higher plants with an emphasis on sorghum. J Integr Plant Biol. 2011;53(3):212-31.

7. Wei K, Chen J, Wang Y, Chen Y, Chen S, Lin Y, et al. Genome-wide analysis of bZIP-encoding genes in maize. DNA Res. 2012;19(6):463-76.

8. Liu J, Chen N, Chen F, Cai B, Dal Santo S, Tornielli GB, et al. Genome-wide analysis and expression profile of the bZIP transcription factor gene family in grapevine (Vitis vinifera). BMC Genomics. 2014;15:281.

9. Baloglu MC, Eldem V, Hajyzadeh M, Unver T. Genome-wide analysis of the bZIP transcription factors in cucumber. PLoS One. 2014;9(4):e96014.

10. Jin Z, Xu W, Liu A. Genomic surveys and expression analysis of bZIP gene family in castor bean (Ricinus communis L.). Planta. 2014;239(2):299-312.

11. Pourabed E, Ghane GF, Soleymani MP, Razavi SM, Shobbar ZS. Basic leucine zipper family in barley: genome-wide characterization of members and expression analysis. Molecular Biotech. 2015;57(1):12-26.

12. Schmutz J, Cannon SB, Schlueter J, Ma J, Mitros T, Nelson W, et al. Genome sequence of the palaeopolyploid soybean. Nature. 2010;463(7278):178-83.

13. Rodriguez-Uribe $L, O^{\prime} C o n n e l l ~ M A$. A root-specific bZIP transcription factor is responsive to water deficit stress in tepary bean (Phaseolus acutifolius) and common bean (P. vulgaris). J Exp Bot. 2006;57(6):1391-8.

14. Jaillon O, Aury JM, Noel B, Policriti A, Clepet C, Casagrande A, et al. The grapevine genome sequence suggests ancestral hexaploidization in major angiosperm phyla. Nature. 2007;449(7161):463-7.

15. Chern MS, Eiben HG, Bustos MM. The developmentally regulated bZIP factor ROM1 modulates transcription from lectin and storage protein genes in bean embryos. Plant J. 1996;10(1):135-48.

16. Izawa T, Foster R, Nakajima M, Shimamoto K, Chua NH. The rice bZIP transcriptional activator RITA-1 is highly expressed during seed development. Plant Cell. 1994;6(9):1277-87.

17. Walsh J, Waters CA, Freeling M. The maize gene liguleless2 encodes a basic leucine zipper protein involved in the establishment of the leaf blade-sheath boundary. Genes Dev. 1998;12(2):208-18.

18. Chuang CF, Running MP, Williams RW, Meyerowitz EM. The PERIANTHIA gene encodes a bZIP protein involved in the determination of floral organ number in Arabidopsis thaliana. Genes Dev. 1999;13(3):334-44.

19. Abe M, Kobayashi Y, Yamamoto S, Daimon Y, Yamaguchi A, Ikeda Y, et al. FD, a bZIP protein mediating signals from the floral pathway integrator FT at the shoot apex. Science. 2005;309(5737):1052-6.

20. Shen $H$, Cao K, Wang $X$. A conserved proline residue in the leucine zipper region of AtbZIP34 and AtbZIP61 in Arabidopsis thaliana interferes with the formation of homodimer. Biochem Biophys Res Commun. 2007;362(2):425-30.

21. Lara P, Onate-Sanchez L, Abraham Z, Ferrandiz C, Diaz I, Carbonero P, et al. Synergistic activation of seed storage protein gene expression in Arabidopsis by ABI3 and two bZIPs related to OPAQUE2. J Biol Chem. 2003;278(23):21003-11.

22. Uno Y, Furihata T, Abe H, Yoshida R, Shinozaki K, Yamaguchi-Shinozaki K. Arabidopsis basic leucine zipper transcription factors involved in an abscisic acid-dependent signal transduction pathway under drought and high-salinity conditions. Proc Natl Acad Sci U S A. 2000;97(21):11632-7. 
23. Lee TH, Tang H, Wang $X$, Paterson AH. PGDD: a database of gene and genome duplication in plants. Nucleic Acids Res. 2013:41(Database issue):D1152-8.

24. Yang Z, Nielsen R. Estimating synonymous and nonsynonymous substitution rates under realistic evolutionary models. Mol Biol Evol. 2000;17(1):32-43.

25. Michelmore RW, Meyers BC. Clusters of resistance genes in plants evolve by divergent selection and a birth-and-death process. Genome Res. 1998;8(11):1113-30.

26. Arabidopsis Genome and Initiative. Analysis of the genome sequence of the flowering plant Arabidopsis thaliana. Nature. 2000;408(6814):796-815.

27. Liao Y, Zou HF, Wei W, Hao YJ, Tian AG, Huang J, et al. Soybean GmbZIP44, GmbZIP62 and GmbZIP78 genes function as negative regulator of ABA signaling and confer salt and freezing tolerance in transgenic Arabidopsis. Planta. 2008;228(2):225-40.

28. Sato S, Nakamura Y, Kaneko T, Asamizu E, Kato T, Nakao M, et al. Genome structure of the legume, Lotus japonicus. DNA Res. 2008;15(4):227-39.

29. Young ND, Debelle F, Oldroyd GE, Geurts R, Cannon SB, Udvardi MK, et al. The Medicago genome provides insight into the evolution of rhizobial symbioses. Nature. 2011;480(7378):520-4.

30. Varshney RK, Chen W, Li Y, Bharti AK, Saxena RK, Schlueter JA, et al. Draft genome sequence of pigeonpea (Cajanus cajan), an orphan legume crop of resource-poor farmers. Nat Biotechnol. 2012;30(1):83-9.

31. Varshney RK, Song C, Saxena RK, Azam S, Yu S, Sharpe AG, et al. Draft genome sequence of chickpea (Cicer arietinum) provides a resource for trait improvement. Nat Biotechnol. 2013;31(3):240-6.

32. Schmutz J, McClean PE, Mamidi S, Wu GA, Cannon SB, Grimwood J, et al. A reference genome for common bean and genome-wide analysis of dual domestications. Nat Genet. 2014;46(7):707-13.

33. Onodera $Y$, Suzuki A, Wu CY, Washida H, Takaiwa F. A rice functional transcriptional activator, RISBZ1, responsible for endosperm-specific expression of storage protein genes through GCN4 motif. J Biol Chem. 2001;276(17):14139-52

34. Fawcett JA, Maere S, Van de Peer Y. Plants with double genomes might have had a better chance to survive the Cretaceous-Tertiary extinction event. Proc Natl Acad Sci U S A. 2009;106(14):5737-42.

35. Cannon SB, llut D, Farmer AD, Maki SL, May GD, Singer SR, et al. Polyploidy did not predate the evolution of nodulation in all legumes. PLoS One. 2010;5(7):e11630.

36. Young ND, Bharti AK. Genome-enabled insights into legume biology. Annu Rev Plant Biol. 2012;63:283-305.

37. Apweiler R, Attwood TK, Bairoch A, Bateman A, Birney E, Biswas M, et al. The InterPro database, an integrated documentation resource for protein families, domains and functional sites. Nucleic Acids Res. 2001;29(1):37-40.

38. Mitchell A, Chang HY, Daugherty L, Fraser M, Hunter S, Lopez R, et al. The InterPro protein families database: the classification resource after 15 years. Nucleic Acids Res. 2015;43(Database issue):D213-21.

39. Katoh K, Standley DM. MAFFT multiple sequence alignment software version 7: improvements in performance and usability. Mol Biol Evol. 2013;30(4):772-80

40. Thompson JD, Gibson TJ, Plewniak F, Jeanmougin F, Higgins DG. The CLUSTAL_X windows interface: flexible strategies for multiple sequence alignment aided by quality analysis tools. Nucleic Acids Res. 1997;25(24):4876-82.

41. Guindon S, Dufayard JF, Lefort V, Anisimova M, Hordijk W, Gascuel O. New algorithms and methods to estimate maximum-likelihood phylogenies: assessing the performance of PhyML 3.0. Syst Biol. 2010;59(3):307-21.

42. Darriba D, Taboada GL, Doallo R, Posada D. ProtTest 3: fast selection of best-fit models of protein evolution. Bioinformatics. 2011;27(8):1164-5.

43. Tamura K, Peterson D, Peterson N, Stecher G, Nei M, Kumar S. MEGA5: molecular evolutionary genetics analysis using maximum likelihood, evolutionary distance, and maximum parsimony methods. Mol Biol Evol. 2011;28(10):2731-9.

44. Guo AY, Zhu QH, Chen X, Luo JC. GSDS: a gene structure display server. Yi Chuan Xue Bao. 2007;29(8):1023-6.

45. Birney E, Clamp M, Durbin R. GeneWise and Genomewise. Genome Res. 2004;14(5):988-95.

46. Bailey TL, Boden M, Buske FA, Frith M, Grant CE, Clementi L, et al. MEME SUITE: tools for motif discovery and searching. Nucleic Acids Res. 2009; 37(Web Server issue):W202-8.

47. Severin AJ, Woody JL, Bolon YT, Joseph B, Diers BW, Farmer AD, et al. RNA-Seq Atlas of Glycine max: a guide to the soybean transcriptome. BMC Plant Biol. 2010;10:160
48. O'Rourke JA, Iniguez LP, Fu F, Bucciarelli B, Miller SS, Jackson SA, et al. An RNA-Seq based gene expression atlas of the common bean. BMC Genomics. 2014;15:866.

49. Benedito VA, Torres-Jerez I, Murray JD, Andriankaja A, Allen S, Kakar K, et al. A gene expression atlas of the model legume Medicago truncatula. Plant J. 2008;55(3):504-13.

50. He J, Benedito VA, Wang M, Murray JD, Zhao PX, Tang Y, et al. The Medicago truncatula gene expression atlas web server. BMC Bioinformatics. 2009;10:441.

51. Verdier J, Torres-Jerez I, Wang M, Andriankaja A, Allen SN, He J, et al. Establishment of the Lotus japonicus Gene Expression Atlas (LjGEA) and its use to explore legume seed maturation. Plant J. 2013;74(2):351-62.

52. Zhang JY, Cruz DECMH, Torres-Jerez I, Kang Y, Allen SN, Huhman DV, et al. Global reprogramming of transcription and metabolism in Medicago truncatula during progressive drought and after rewatering. Plant Cell Environ. 2014;37(11):2553-76.

53. Li D, Su Z, Dong J, Wang T. An expression database for roots of the model legume Medicago truncatula under salt stress. BMC Genomics. 2009;10:517.

54. Nantel A, Quatrano RS. Characterization of three rice basic/leucine zipper factors, including two inhibitors of EmBP-1 DNA binding activity. The Journal of biological chemistry. 1996;271(49):31296-305.

55. Boudet N, Aubourg S, Toffano-Nioche C, Kreis M, Lecharny A. Evolution of intron/exon structure of DEAD helicase family genes in Arabidopsis, Caenorhabditis, and Drosophila. Genome Res. 2001;11(12):2101-14.

56. Wang N, Zheng Y, Xin H, Fang L, Li S. Comprehensive analysis of NAC domain transcription factor gene family in Vitis vinifera. Plant Cell Rep. 2013;32(1):61-75.

57. Suckow M, Schwamborn K, Kisters-Woike B, von Wilcken-Bergmann B, Muller-Hill B. Replacement of invariant bZip residues within the basic region of the yeast transcriptional activator GCN4 can change its DNA binding specificity. Nucleic Acids Res. 1994;22(21):4395-404.

58. Niu X, Renshaw-Gegg L, Miller L, Guiltinan MJ. Bipartite determinants of DNA-binding specificity of plant basic leucine zipper proteins. Plant Mol Biol. 1999;41(1):1-13.

59. Suckow M, von Wilcken-Bergmann B, Muller-Hill B. Identification of three residues in the basic regions of the bZIP proteins GCN4, C/EBP and TAF-1 that are involved in specific DNA binding. EMBO J. 1993;12(3):1193-200.

60. Landschulz WH, Johnson PF, McKnight SL. The leucine zipper: a hypothetical structure common to a new class of DNA binding proteins. Science. 1988;240(4860):1759-64.

61. Ellenberger TE, Brandl CJ, Struhl K, Harrison SC. The GCN4 basic region leucine zipper binds DNA as a dimer of uninterrupted alpha helices: crystal structure of the protein-DNA complex. Cell. 1992;71(7):1223-37.

62. O'Shea EK, Rutkowski R, Kim PS. Mechanism of specificity in the Fos-Jun oncoprotein heterodimer. Cell. 1992;68(4):699-708.

63. McLachlan AD, Stewart M. Tropomyosin coiled-coil interactions: evidence for an unstaggered structure. J Mol Biol. 1975;98(2):293-304.

64. Deppmann CD, Acharya A, Rishi V, Wobbes B, Smeekens S, Taparowsky EJ, et al. Dimerization specificity of all 67 B-ZIP motifs in Arabidopsis thaliana: a comparison to Homo sapiens B-ZIP motifs. Nucleic Acids Res. 2004;32(11):3435-45.

65. Thompson KS, Vinson CR, Freire E. Thermodynamic characterization of the structural stability of the coiled-coil region of the bZIP transcription factor GCN4. Biochemistry. 1993;32(21):5491-6.

66. Zeng X, Herndon AM, Hu JC. Buried asparagines determine the dimerization specificities of leucine zipper mutants. Proc Natl Acad Sci U S A. 1997;94(8):3673-8

67. Moitra J, Szilak L, Krylov D, Vinson C. Leucine is the most stabilizing aliphatic amino acid in the $\mathrm{d}$ position of a dimeric leucine zipper coiled coil. Biochemistry. 1997;36(41):12567-73.

68. Vinson CR, Hai T, Boyd SM. Dimerization specificity of the leucine zipper-containing bZIP motif on DNA binding: prediction and rational design. Genes Dev. 1993;7(6):1047-58.

69. Fassler J, Landsman D, Acharya A, Moll JR, Bonovich M, Vinson C. B-ZIP proteins encoded by the Drosophila genome: evaluation of potential dimerization partners. Genome Res. 2002;12(8):1190-200.

70. Vinson C, Myakishev M, Acharya A, Mir AA, Moll JR, Bonovich M. Classification of human B-ZIP proteins based on dimerization properties. Mol Cell Biol. 2002;22(18):6321-35.

71. Finkelstein RR, Lynch TJ. The Arabidopsis abscisic acid response gene ABI5 encodes a basic leucine zipper transcription factor. The Plant cell. 2000;12(4):599-609. 
72. Bensmihen S, Giraudat J, Parcy F. Characterization of three homologous basic leucine zipper transcription factors (bZIP) of the ABI5 family during Arabidopsis thaliana embryo maturation. J Exp Bot. 2005;56(412):597-603

73. Schmidt RJ, Burr FA, Aukerman MJ, Burr B. Maize regulatory gene opaque-2 encodes a protein with a "leucine-zipper" motif that binds to zein DNA. Proc Natl Acad Sci U S A. 1990;87(1):46-50.

74. Lohmer S, Maddaloni M, Motto M, Di Fonzo N, Hartings H, Salamini F, et al. The maize regulatory locus Opaque-2 encodes a DNA-binding protein which activates the transcription of the b-32 gene. The EMBO journal. 1991;10(3):617-24.

75. Brochetto-Braga MR, Leite A, Arruda P. Partial purification and characterization of lysine-ketoglutarate reductase in normal and opaque-2 maize endosperms. Plant Physiol. 1992;98(3):1139-47.

76. Yunes JA, Cord NG, Leite A, Ottoboni LM, Arruda P. The role of the Opaque2 transcriptional factor in the regulation of protein accumulation and amino acid metabolism in maize seeds. An Acad Bras Cienc. 1994;66 Su 1(Pt 2):227-37. quiz 237-8.

77. Hanson J, Smeekens S. Sugar perception and signaling-an update. Curr Opin Plant Biol. 2009;12(5):562-7.

78. Smeekens S, Ma J, Hanson J, Rolland F. Sugar signals and molecular networks controlling plant growth. Curr Opin Plant Biol. 2010;13(3):274-9.

79. Hossain MA, Cho Jl, Han M, Ahn CH, Jeon JS, An G, et al. The ABRE-binding bZIP transcription factor OSABF2 is a positive regulator of abiotic stress and ABA signaling in rice. J Plant Physiol. 2010;167(17):1512-20.

80. Yoshida T, Fujita Y, Sayama H, Kidokoro S, Maruyama K, Mizoi J, et al. AREB1, AREB2, and ABF3 are master transcription factors that cooperatively regulate ABRE-dependent ABA signaling involved in drought stress tolerance and require ABA for full activation. Plant J. 2010;61(4):672-85.

81. Hartmann L, Pedrotti L, Weiste C, Fekete A, Schierstaedt J, Gottler J, et al. Crosstalk between Two bZIP Signaling Pathways Orchestrates Salt-Induced Metabolic Reprogramming in Arabidopsis Roots. The Plant cell. 2015;27(8):2244-60.

82. Weltmeier F, Rahmani F, Ehlert A, Dietrich K, Schutze K, Wang X, et al. Expression patterns within the Arabidopsis C/S1 bZIP transcription factor network: availability of heterodimerization partners controls gene expression during stress response and development. Plant Mol Biol. 2009;69(1-2):107-19.

83. Sun X, Li Y, Cai H, Bai X, Ji W, Ding X, et al. The Arabidopsis AtbZIP1 transcription factor is a positive regulator of plant tolerance to salt, osmotic and drought stresses. J Plant Res. 2012;125(3):429-38.

\section{Submit your next manuscript to BioMed Central and we will help you at every step:}

- We accept pre-submission inquiries

- Our selector tool helps you to find the most relevant journal

- We provide round the clock customer support

- Convenient online submission

- Thorough peer review

- Inclusion in PubMed and all major indexing services

- Maximum visibility for your research 